Article

\title{
Experimental Studies on Thermophysical and Electrical Properties of Graphene-Transformer Oil Nanofluid
}

\author{
Charishma Almeida ${ }^{1}$, Sohan Paul ${ }^{1}$, Lazarus Godson Asirvatham ${ }^{1, *} \mathbb{C}$, Stephen Manova ${ }^{1}(\mathbb{D}$, \\ Rajesh Nimmagadda ${ }^{2} \mathbb{D}$, Jefferson Raja Bose ${ }^{1} \mathbb{D}$ and Somchai Wongwises ${ }^{3,4}$ \\ 1 Department of Mechanical Engineering, Karunya Institute of Technology and Sciences, \\ Coimbatore 641114, India; charishma.almeida@yahoo.com (C.A.); sohanpaul996@gmail.com (S.P.); \\ manovas@karunya.edu.in (S.M.); jefferson@karunya.edu (J.R.B.) \\ 2 Center for Advanced Energy Studies, Koneru Lakshmaiah Educational Foundation, \\ Vaddeswaram 522502, A.P., India; rajesh.mech335@gmail.com \\ 3 Department of Mechanical Engineering, Faculty of Engineering, King Mongkut's University of Technology \\ Thonburi (KMUTT), Bangkok 10140, Thailand; somchai.won@kmutt.ac.th \\ 4 National Science and Technology Development Agency (NSTDA), Pathum Thani 12120, Thailand \\ * Correspondence: godson@karunya.edu
}

Received: 9 September 2020; Accepted: 1 October 2020; Published: 3 October 2020

\begin{abstract}
The thermophysical and electrical properties of graphene-transformer oil nanofluid at three weight percentage concentrations $(0.01 \%, 0.03 \%$, and $0.05 \%)$ were experimentally studied. Experiments conducted to find viscosity, surface tension, density, specific resistance, electrical conductivity, and dielectric dissipation at various temperatures ranging from $20^{\circ} \mathrm{C}$ to $90{ }^{\circ} \mathrm{C}$. It was noted that the nanofluid with $0.05 \%$ concentration showed an enhancement of $2.5 \%$ and $16.6 \%$ for density and viscosity, respectively, when compared to transformer oil. In addition, an average reduction in surface tension is noted to be $10.1 \%$ for the maximum concentration of nanofluid. Increase in heat load and concentration improves Brownian motion and decreases the cohesive force between these particles, which results in a reduction in surface tension and increases the heat-transfer rate compared to transformer oil. In addition, for the maximum concentration of nanoparticles, the electrical conductivity of nanofluid was observed to be 3.76 times higher than that of the transformer oil at $90^{\circ} \mathrm{C}$. The addition of nanoparticles in the transformer oil decreases the specific resistance and improves the electrical conductivity thereby enhancing the breakdown voltage. Moreover, the thermophysics responsible for the improvement in thermophysical and electrical properties are discussed clearly, which will be highly useful for the design of power transmission/distribution systems.
\end{abstract}

Keywords: transformer oil; nanofluid; electrical conductivity; surface tension; viscosity

\section{Introduction}

The increase in the demand of electricity has led to the development of transmission and distribution system in electrical network. In these transmission system, oil-immersed transformers are widely used due to their high-voltage transferring capacity from one circuit to the other. However, transferring high voltages leads to an increase in internal heat generation and power dissipation of the transformer [1]. The statistical report confirms that, due to poor thermophysical and dielectric properties of the transformer oil, the life span of a transformer is decreased to 17.8 years, which is practically half of its expected life (35-40 years) [2]. Thus, the stable operation and the reliability of a transformer relies mainly on the thermophysical and dielectric properties of the transformer oil 
used. Conventional petroleum-based mineral oils were used to extract the heat that is generated $\left(I^{2} R\right.$ losses) due to the resistance in the primary and secondary windings and the current flowing through them [3]. However, when transferring higher voltage, its potential for using as a cooling medium is limited due to its poor thermophysical and dielectric properties. In order to enhance these properties, many research works have been carried out by replacing the conventional mineral oil with vegetable oils, as they possess good insulation and cooling characteristics. However, these kinds of oils become contaminated even in safe operating conditions and lead to degradation [4]. This degradation results in chemical reactions with the internal parts of the transformer, which increases the possibility of transformer faults, financial losses, and long-term shutdown [5]. Therefore, the study on enhancing the heat transfer and dielectric properties of a transformer oil without any degradation in its quality for a long-time run is still an active research topic in heat-transfer engineering.

In this regard, nanoparticles suspended in a base fluid are considered to be of great interest to enhance the thermophysical and dielectric properties. These nanoparticle-based fluids termed as nanofluids have a wide variety of applications [6-10]. Many experimental works have been carried out with nanofluids and proved their significance of employing it in industrial cooling applications [11-13]. In addition to the experimental works, prediction on the performance of nanofluids were also performed, relating the influential factors such as concentration, type, and size of nanoparticles and temperature [14-16]. Based on the machine learning approaches, such as artificial neural network (ANN), least square support vector machine (LSSVM), etc., an accurate model was also developed to predict the thermophysical properties of nanofluid [17-19]. Even though numerical approaches result in an easier way to predict their properties, the knowledge on the performance of nanofluids through experimental findings is much more essential for real time application. However, very few experimental works have been carried out by suspending metallic nanoparticles in the transformer oil thereby using it in cooling applications. In addition, no work has been done to date using graphene nanoparticles suspended in transformer oil thereby to enhance both the thermophysical and dielectric properties. Thus, employing a nanoparticle suspended in transformer oil with higher thermophysical and electrical characteristics for improving the life of the transformer is very much essential in the field of transmission and distribution system. Therefore, in this proposed work, the thermophysical and electrical properties of a graphene-transformer oil nanofluid is experimentally tested for different weight percentage concentrations and for different temperatures.

Some of the most productive works to enhance the thermophysical and dielectric properties are mentioned below.

Zeng et al. [20] dispersed surface-modified $\mathrm{MoS}_{2}$ nanoparticles in a heat-transfer oil B350 (dibenzyl toluene). It was found that, the thermal conductivity of the nanofluid increased with an increase in mass fraction of nanoparticles. When $\mathrm{Al}_{2} \mathrm{O}_{3}$ nanoparticles were dispersed in transformer oil, the oil mixtures showed higher thermal conductivity, convective heat-transfer coefficient, and natural convection properties compared to oil. Li et al. [21] dispersed Cu nanoparticles in kerosene, toluene, and decahydronaphthalene oils. It was noted that the higher viscosity and thermal conductivity values are recorded for nanofluids than the base fluids. When $\mathrm{SiO}_{2}$ nanoparticles were dispersed in ethylene glycol or water, the viscosity of the nanofluid increased with volume concentration. However, the particle size, shape, and distribution and particle fluid interaction are the other factors that have significant effect on thermal conductivity and heat-transfer coefficient.

For a transformer oil, along with its thermophysical properties, the electrical properties such as breakdown voltage, specific resistivity, and dielectric dissipation factor (DDF) has much significance. Rafiq et al. [22] illustrated the importance of selection and addition of nanoparticles to avoid agglomeration, as it can lead to negative impact on a fluid's electrical properties. Cao et al. [23] dispersed solid particles of $\mathrm{Cu}, \mathrm{Al}_{2} \mathrm{O}_{3}, \mathrm{TiO}_{2}$, and $\mathrm{SiC}$ in the transformer oil and used them as a cooling medium instead of transformer oil. It was observed that, despite having good heat-transfer characteristics, the nanoparticles also enhance the dielectric capacity of oil and the breakdown voltage. $\mathrm{The}_{\mathrm{TiO}}$ nanoparticles were dispersed in mineral transformer oil by Nguyen et al. [24]. It was reported that the 
breakdown voltage of nanofluid increased that of the transformer oil, respectively. Hanai et al. [25] dispersed $\mathrm{TiO}_{2}$-anatase, $\mathrm{TiO}_{2}$-rutile, and $\mathrm{ZnO}$ metal oxide nanoparticles to mineral oil and alkyl benzene. It was noted that, irrespective of the kind of nanoparticle or base oils used, there was an increase in the breakdown voltage for less than $0.05 \mathrm{vol} \%$. In addition, when the concentration of particles exceeded $0.05 \mathrm{vol} \%$, the breakdown voltage decreased.

Karthik et al. [26] analyzed the critical parameters such as viscosity, breakdown voltage, flash point, fire point, and $\mathrm{p}-\mathrm{H}$ value of transformer oil nanofluid. Aluminum oxide, aluminum, copper oxide, and copper nanoparticles were dispersed in the base fluid. Breakdown voltage of nanofluids was found slightly lower than transformer oil, while nanofluids showed significant enhancement in viscosity, flash, and fire point. When multiwalled carbon nanotubes were dispersed in transformer oil, Beheshti et al. [27] observed no significant change in electrical conductivity with an increase in concentration and temperature. However, the increase in temperature of the nanofluids led to an increase in thermal conductivity but decrease in viscosity compared to the transformer oil. When ceramic-zirconia $\left(\mathrm{ZrO}_{2}\right)$ and titania $\left(\mathrm{TiO}_{2}\right)$ were suspended in the transformer oil by Pugazhendhi et al. [28], breakdown voltage values were found to be higher in $\mathrm{TiO}_{2}$ nanofluid when compared to $\mathrm{ZrO}_{2}$ nanofluid. In addition, kinematic viscosities of $\mathrm{TiO}_{2}$ nanofluid were higher than $\mathrm{ZrO}_{2}$. The transformer oil dispersed with silica and silver supported on silica were investigated by Botha and Ndungu [29].

In addition to experimental works, few numerical works have been carried out to predict the thermophysical properties of nanofluid. Asadi et al. [30] critically reviewed the recent development in the thermophysical properties and preparation of oil-based nanofluids. Major influencing parameters such as experimental temperature, size/shape of nanoparticles, and concentration of the nanoparticle were discussed clearly with the mechanisms involved in it. In addition, theoretical correlations to calculate the thermophysical properties of oil-based nanofluid were also presented. Benos et al. [31] proposed an analytical work to predict the heat-transfer performance of carbon nanotube (CNT) nanofluid with internal heating under the influence of external magnetic field. It was stated that the rheological properties of the nanofluid influences more on the flow characteristics and heat-transfer performance. In addition, the authors suggested that the theoretical model will be a useful tool for future engineering and biomedical applications. Moreover, adding nanoparticles in the hydrodynamic flow regime will enhance the heat-transfer performance of nanofluid. However, it is stated that the performance deterioration was observed in the presence of a magnetic field [32].

Based on the study of above literatures, it is clearly observed that with an increase in temperature and volume concentration of nanoparticles, the thermophysical properties of the nanofluid are enhanced. Many research works have been carried out to measure the properties of nanofluid with a relatively higher volume concentration using the metal oxide nanoparticles. In addition, the experimental works are carried at ambient temperature for different types of metallic oxide particles such as $\mathrm{Al}_{2} \mathrm{O}_{3}, \mathrm{CuO}, \mathrm{Fe}_{3} \mathrm{O}_{4}, \mathrm{TiO}_{2}$, and $\mathrm{SiC}$. Only a few works have been done on graphene-transformer oil to measure the thermophysical and electrical properties of graphene-transformer oil nanofluid. Moreover, the experimental studies involving thermophysical and electrical properties of nanofluids having higher thermal conductivity metallic nanoparticles such as $\mathrm{Cu}, \mathrm{Al}$, and graphene are found to be limited and insufficient to accurately predict the properties of these fluids through an artificial intelligence approach. In addition, a detailed study on the mechanisms involving in enhancement of thermophysical and electrical properties of nanofluids is very much essential in the present context. Thus, the present work deals with the measurement of thermophysical properties and electrical properties of graphene-transformer oil nanofluid for the lower weight percentage concentration $(0.01,0.03$, and $0.05 \%)$ of graphene and for the temperature ranging from $20^{\circ} \mathrm{C}$ to $90^{\circ} \mathrm{C}$. In addition, the effect of viscosity, surface tension, and the electrical resistivity on the heat-transfer performance of graphene-transformer nanofluid is explained in detail with the mechanisms involved. The use of transformer oil reduces the risk of oil spills and also the disposal of waste oil. It appreciably reduces the cost of new oil, and thus, it is an eco-friendly solution. 


\section{Experimentation}

\subsection{Preparation of Nanofluid}

The transformer oil used for the experiment was transformer oil obtained from Transformer Oil Reclamation Plant, Coimbatore, Tamil Nadu, India. The oil was developed by the principle of sorbent reactivation that uses Fuller's Earth as the sorbent material. The transformer oil contained $15 \%$ of recycled oil added to the new transformer oil. The graphene-transformer oil nanofluid was prepared by sonicating the mixture using ultrasonic vibrator for $30 \mathrm{~min}$, which reduces the nanoparticle agglomeration. The graphene nanoparticle was purchased from Sky Spring Nanomaterials, Inc., Houston, USA (product number-0540DX, lot number 0540-061814). The graphene-transformer oil nanofluid was prepared for three different weight percentage concentrations of $0.01 \%, 0.03 \%$, and $0.05 \%$, by dispersing the determined amount of graphene nanoparticles in the base fluid, as shown in Figure 1.

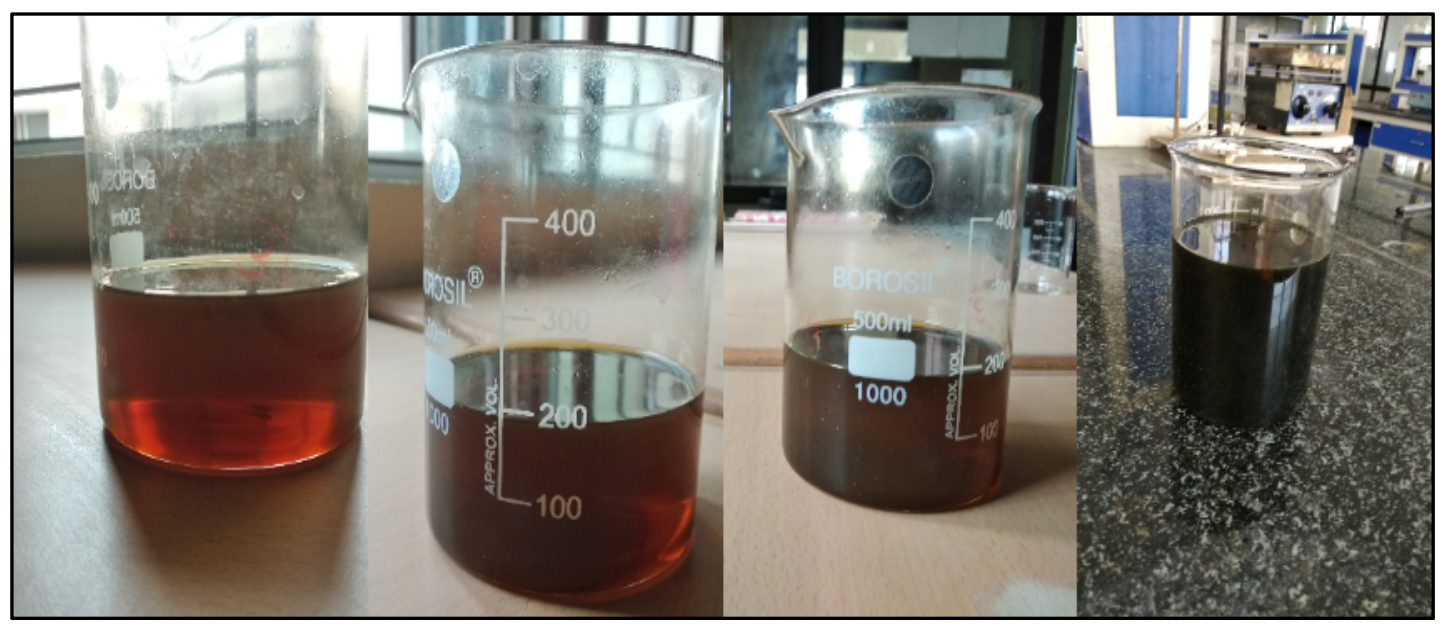

Figure 1. Transformer oil samples with $0 \%, 0.01 \%, 0.03 \%$, and $0.05 \%$ weight percentage concentration of graphene nanoparticle.

\subsection{Measurement of Thermophysical and Electrical Properties}

\subsubsection{Measurement of Viscosity}

The viscosity of a working fluid at a given shear rate was measured using the Brookfield digital viscometer (DV-E, Brookfield, USA), which works on the principle of rotational viscometer. The viscosity of any fluid is a measure of amount of torque that is required to rotate the spindle in a particular fluid. A cylindrical spindle or a disk was immersed in the fluid to which the torque was applied through a calibrated spring. The deflection in the spring was measured using a rotary transducer, which indicated the viscous drag of the fluid that was exerted against the spindle. Thus, the viscous drag in the fluid is directly proportional to the torque required to rotate the spindle. The accuracy and the repeatability in the torque measurement was $1 \%$ and $0.2 \%$, respectively. A water circulating bath was used to maintain constant temperature of the nanofluid between $-10{ }^{\circ} \mathrm{C}$ and $100{ }^{\circ} \mathrm{C}$. A chamber tube made of glass was used, which holds the nanofluid during the experiment, and a water jacket was used to circulate the constant-temperature water through it. In order to avoid heat leak, the water jacket was thermally insulated. The constant-temperature water was made to flow through the water jacket using a pump, and the chamber was held firmly on a stand to avoid vibration. The viscometer was initially calibrated by measuring the viscosity of oil. Moreover, the experiments were repeated 3 times to calculate the average viscosity values. Then, the viscosities of the graphene-transformer oil nanofluids with volume concentrations of $0.01,0.02$, and $0.03 \%$ were carried out for the temperatures ranging from $10{ }^{\circ} \mathrm{C}$ and $60{ }^{\circ} \mathrm{C}$. In this proposed work, the viscosity of graphene-transformer oil nanofluid was found through experiments. However, the viscosity of nanofluid can be determined 
using Brinkman extended model [33], which is applicable up to $4 \%$ weight concentration and the equation is given as:

$$
\frac{\mu_{\mathrm{nf}}}{\mu_{\mathrm{oil}}}=\left(\frac{1}{(1-\Phi)^{2.5}}\right)
$$

where $\mu_{\mathrm{nf}}$ and $\mu_{\mathrm{oil}}$ are the viscosities of nanofluid and transformer oil, respectively. $\Phi$ represents the concentration of nanoparticles in the base fluid.

\subsubsection{Measurement of Surface Tension}

The inward pull by the molecules at the interface is known as surface tension. Unlike in the bulk liquid, the surface of nanofluids lacks even distribution of molecules, due to which a film is formed at the surface. Thus, the surface tension is a measure of force that is required to break the surface film for a particular length. The dynamic surface tension is measured using SITA DynoTester (SITA Process Solutions, Germany) that works on the principle of maximum bubble pressure. The resolution and the measuring range of the DynoTester are given as $0.1 \mathrm{mN}$ and $15-100 \mathrm{~m}^{-1}$, respectively. Initially the surface tension of transformer oil was measured to calibrate the instrument. Repetitions were carried out 3 times at different temperatures to calculate the average surface tension value, and the deviations are noted to be $\pm 1.2 \%$ from the mean value. Then, the surface tension of graphene-transformer oil nanofluids for the concentrations of $0.05,0.01,0.02$, and $0.03 \%$ was conducted at different temperatures ranging from $10{ }^{\circ} \mathrm{C}$ to $60^{\circ} \mathrm{C}$. For every experiment, freshly prepared nanofluids were used, particularly at higher temperatures, as the evaporation rate was higher. In addition, a constant-temperature water bath and a circulating jacket were used to measure surface tension for graphene-transformer oil nanofluid at different temperatures.

\subsubsection{Measurement of Density}

The density of the sample is measured using a hygrometer. It consists of a sealed hollow glass tube and ballast for stability such as lead or mercury. The tube has graduations for measuring the density along the narrow stem. It makes use of Archimedes' principle. A tall container with oil sample to be tested was taken, and the hydrometer was gently lowered into the oil sample until it floated freely. The point at which the surface of the oil sample touches the stem of the hydrometer gives the value of specific gravity through which density can be found. However, the density of any nanofluid can be determined by the correlation [34], which is given as follows:

$$
\rho_{\mathrm{nf}}=\Phi \rho_{\mathrm{np}}+(1-\Phi) \rho_{\mathrm{oil}}
$$

where $\rho_{\mathrm{nf}}, \rho_{\mathrm{np}}$, and $\rho_{\mathrm{oil}}$ are the densities of nanofluid, nanoparticle, and the transformer oil, respectively.

\subsubsection{Measurement of Oil Resistivity}

PE-ORDF-2 Oil resistivity and dissipation factor test set is the apparatus used to measure the specific resistivity and dielectric dissipation factor of the transformer oil, which is shown in Figure 2. It is a three-piece set consisting of the heater unit with stainless steel oil cell, million-mega-ohm meter, and the dissipation factor bridge to derive the readings. Maximum test voltages of $500 \mathrm{~V}$ DC and $1000 \mathrm{~V}$ DC are available for insulation resistance testing instrument. The oil samples of $50 \mathrm{~mL}$ were taken in a three-terminal oil cell, which is made of stainless steel with Teflon as the insulating material. The cell was rinsed with a portion of oil sample, drained, and discarded. Then, the cell was refilled, and care was taken to avoid the entrapment of air bubbles. The cell and the contents were brought to the required test temperature. Within $10 \mathrm{~min}$ of the temperature reaching $\pm 1{ }^{\circ} \mathrm{C}$ of the required test temperature, the measurement was started. For the test of dielectric dissipation factor, A.C. voltage subjected to the oil sample was between $0.03 \mathrm{kV} / \mathrm{mm}$ and $1 \mathrm{kV} / \mathrm{mm}$, while frequency was between $40 \mathrm{~Hz}$ and $62 \mathrm{~Hz}$. After the test of dielectric dissipation factor, the electrodes were short 
circuited for $60 \mathrm{~s}$ for the measurement of specific resistivity. Electrical connections were established for the measuring apparatus. The inner electrode of the cell was connected to earth, while the outer electrode was connected to the D.C. voltage. At the end of electrification time, the readings were noted. In addition to the specific resistivity of nanofluid that was found through experiments, the resistivity of the graphene-transformer oil can be determined by the following Equation (3). It is known that the electrical conductivity is inversely proportional to resistivity; the expression for finding electrical conductivity is given in Equation (4), which is given as follows [35]:

$$
\begin{gathered}
\Psi_{n f}=\frac{1}{\gamma_{n f}} \\
\frac{\gamma_{n f}}{\gamma_{\mathrm{oil}}}=\frac{2 \gamma_{\mathrm{oil}}+\gamma_{\mathrm{np}}-2\left(\gamma_{\mathrm{oil}}-\gamma_{\mathrm{np}}\right) \Phi}{2 \gamma_{\mathrm{oil}}+\gamma_{\mathrm{np}}+\left(\gamma_{\mathrm{oil}}-\gamma_{\mathrm{np}}\right) \Phi}
\end{gathered}
$$

where $\gamma_{n f}, \gamma_{\mathrm{np}}$, and $\gamma_{\mathrm{oil}}$ are the electrical conductivities of nanofluid, nanoparticle, and the transformer oil, respectively, and $\Psi_{n f}$ is the specific resistivity of the graphene-transformer oil nanofluid.

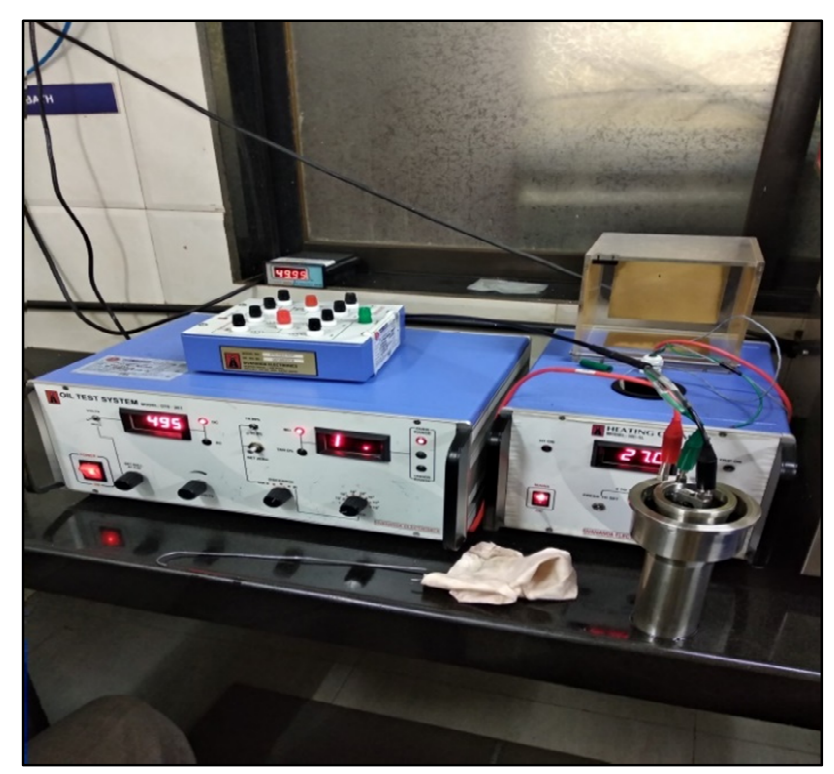

Figure 2. Oil resistivity and dissipation factor test apparatus.

\section{Results and Discussions}

\subsection{Thermophysical and Electrical Properties of Nanofluid}

\subsubsection{Effect of Temperature on Viscosity}

Initially, the properties are tested for transformer oil from temperatures $20^{\circ} \mathrm{C}$ to $60^{\circ} \mathrm{C}$. This is to validate the results with the samples of graphene-transformer oil nanofluid. Figure 3 shows the variation of viscosity of graphene-transformer oil nanofluid with respect to temperature. It can be noted that the viscosity of transformer oil decreases with the increase in temperature. Similarly, the viscosity of transformer oil nanofluid samples also decreases with the increase in the temperature. However, as the weight percentage concentration of graphene nanoparticles increases in the oil, the viscosity also increases. The oil sample with $0.01 \%$ graphene nanoparticles has an increase of $4.49 \%$ of viscosity compared to that of transformer oil. This is due to higher Van der Waals force existing between the nanoparticles and the transformer oil and thus preventing the molecular movement of the oil. While for the oil samples with $0.03 \%$ and $0.05 \%$ graphene nanoparticle concentration the increase in percentage of viscosity is noted to be $9.90 \%$ and $19.88 \%$, respectively. As the particle concentration of 
graphene increases in the oil, the presence of more nanoparticles retards the fluid flow. This makes the nanofluid more viscous, thus reducing the flow rate. However, as the temperature increases, due to higher vibration of the particles in the fluid, heat transfer increases, and hence, viscosity decreases accordingly. This decrease in viscosity leads to better cooling performance of the oil.

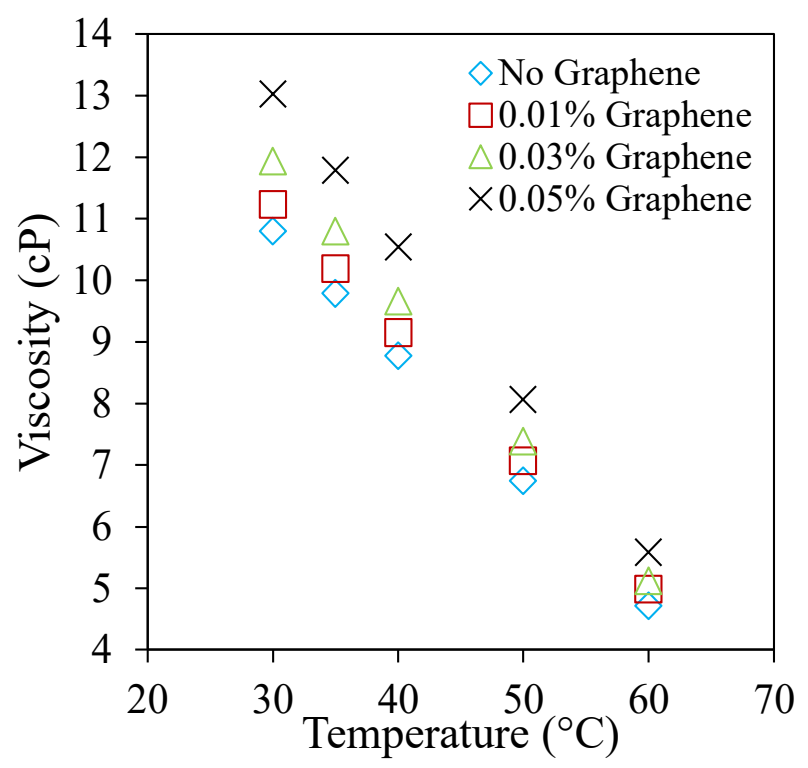

Figure 3. Variation of viscosity of graphene-transformer oil nanofluid with temperature.

\subsubsection{Effect of Temperature on Surface Tension}

The Figure 4 shows the variation in surface tension with temperature for graphene-transformer oil nanofluid. It can be seen that surface tension decreases with the increase in temperature for the transformer oil. In addition, the surface tension for the graphene-transformer oil nanofluid is found to decrease with the increase in temperature. As the weight percentage concentration of graphene increases in the oil, the surface tension decreases. A decrease of $1.77 \%$ of surface tension in $0.01 \%$ of graphene oil sample is found as compared to the transformer oil. Similarly, a decrease of $7.6 \%$ and $10.1 \%$ in surface tension is found in $0.03 \%$ and $0.05 \%$ graphene oil samples, respectively. The surface tension of the working fluid is considered to be of great importance, as this physical phenomenon influences more on the surface wettability. In addition, from the existing literatures, it was noted that the surface tension also influences more on the wettability of nanoparticle [36]. As the weight percentage concentration of graphene nanoparticles increases in the oil, Brownian motion of the nanoparticles also increases. This increase in Brownian motion of the nanoparticles decreases the cohesive force between the particles, and hence, surface tension of the oil decreases. Similarly, as the temperature increases, the vibration of nanoparticles increases, which further leads to a decrease in cohesive force between the particles. Moreover, due to the hydrophobic nature of graphene, adsorption of nanoparticles at the liquid-vapor interface occurs [37]. This leads to a decrease in the surface tension with the increase in temperature as well as particle concentration of graphene. The decrease in surface tension of the oil helps the oil to spread easily in the entire volume of the transformer and reduces the energy loss. However, substantial decrease in surface tension of oil is also not desirable, since it may further lead to a decrease in viscosity, which will deteriorate the quality of the oil. 


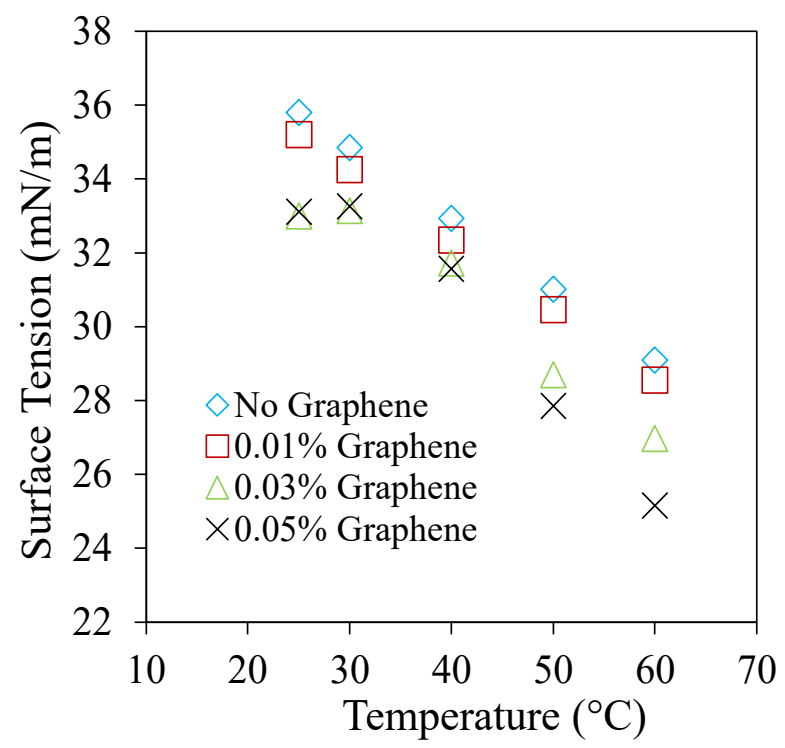

Figure 4. Variation of surface tension of graphene-transformer oil nanofluid with temperature.

\subsubsection{Effect of Temperature on Density}

Figure 5 shows the variation of density with the temperature for the graphene-transformer oil nanofluid. It can be observed that, as temperature increases, the density of the transformer oil decreases. In addition, the density is found to decrease for the graphene oil samples with the increase in temperature. For the $0.01 \%$ graphene oil sample, there is no change in density compared to that of the transformer oil. However, an increase of approximately $0.46 \%$ density is found in both $0.03 \%$ and $0.05 \%$ graphene oil samples compared to that of transformer oil. The decrease in density of transformer oil containing graphene is negligible, which shows that the addition of graphene nanoparticles does not affect the density of the oil. Hence, the kinematic viscosity of the oil is not altered leading to better cooling performance.

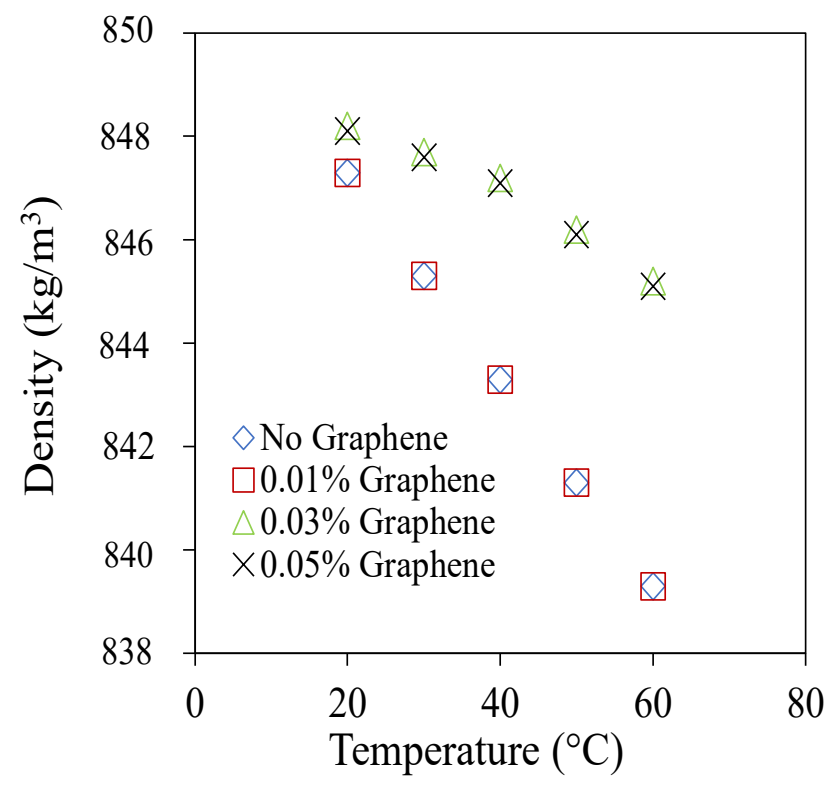

Figure 5. Variation of density of graphene-transformer oil nanofluid with temperature.

\subsubsection{Effect of Temperature on Specific Resistivity of Working Fluid}

The electrical properties of graphene-transformer oil nanofluid are measured for the temperature ranging from $20^{\circ} \mathrm{C}$ to $90^{\circ} \mathrm{C}$. Figure 6 shows the variation in specific resistivity of graphene-transformer 
oil nanofluid with increase in temperature. It can be noticed that as the temperature increases, the specific resistivity of transformer oil and the nanofluid decreases. Based on the measurements, for the increase in weight concentration of nanoparticles, a reduction of $20.47 \%, 64.29 \%$, and $79 \%$ are, respectively, observed for specific resistivity with $0.01 \%, 0.03 \%$, and $0.05 \%$ graphene oil samples when compared to that of transformer oil. For higher temperatures, the increase in the Brownian motion of nanoparticles enhances the movement of negatively charged electrons. This results in faster movement of electrons to the other electrode with a decrease in specific resistivity of graphene-transformer oil nanofluid when compared to that of conventional transformer oil. However, for lower temperatures, the Brownian motion is comparably less, causing higher trapping of electrons and resulting in higher specific resistivity. This shows that the addition of graphene particles in the transformer oil has a considerable effect on the specific resistance. However, there will be a certain limit for the amount of graphene nanoparticles to be suspended beyond which electrical properties of oil can be affected adversely.

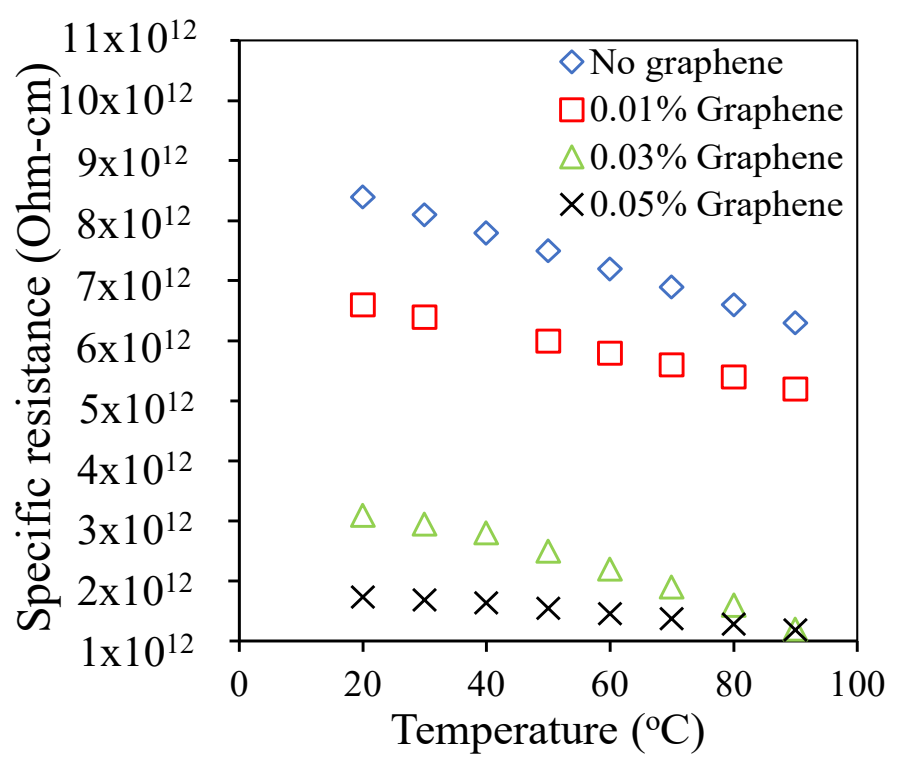

Figure 6. Variation of specific resistivity of graphene-transformer oil nanofluid with temperature.

\subsubsection{Effect of Temperature on Electrical Conductivity}

Figure 7 shows the variation of electrical conductivity with temperature for graphene-transformer oil nanofluid. Based on the experiments, it was observed that as the temperature increases, the electrical conductivity of the transformer oil and the nanofluid increases. From the results, enhancement of $57.8 \%, 75.2 \%$, and $78.9 \%$ are, respectively, observed for $0.01 \%, 0.03 \%$, and $0.05 \%$ concentrations of graphene-transformer oil nanofluid when compared to that of the transformer oil. This shows that the electrical conductivity of $0.03 \%$ graphene oil sample is 2.41 times, and $0.05 \%$ of graphene sample oil is 4.76 times the electrical conductivity of the transformer oil. This is due to the fact that, at higher concentrations, the amount of trapping the fast-moving electrons increases, whereas at lower concentrations, it is comparably less. Thus, at higher concentrations, the electrical conductivity is observed to be higher. Even though there is a tremendous increase in the value of electrical conductivity of the oil, the values are within the limits of IS 335 standards (standard which lays down the quality of transformer oil). However, there is an optimum concentration for the increase in electrical conductivity, and further addition of nanoparticles will result in agglomeration, which may result in negative impact on the electrical properties of the oil. 


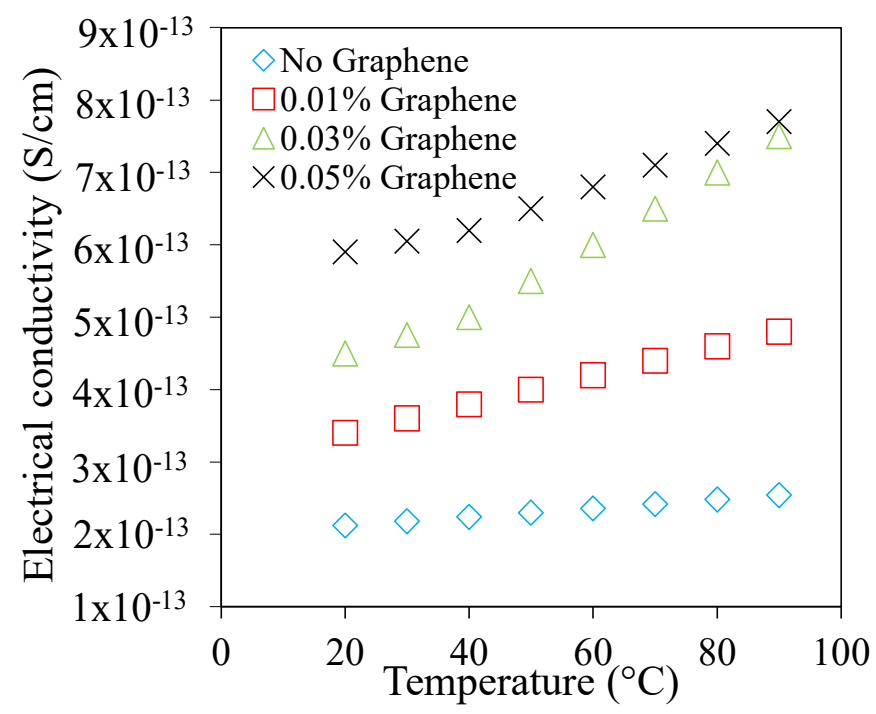

Figure 7. Variation of electrical conductivity of graphene-transformer oil nanofluid with temperature.

\subsubsection{Effect of Temperature on Dielectric Dissipation Factor}

Figure 8 shows the variation of the dielectric dissipation factor (DDF) of transformer oil nanofluid for different temperatures ranging from $20{ }^{\circ} \mathrm{C}$ to $90{ }^{\circ} \mathrm{C}$. It can be seen that, as the weight percentage concentration of graphene nanoparticles increase, there is an increase in the DDF. However, as the temperature increases, there is decrease in the DDF. The increase in the DDF shows that there is an increase in the contamination of the oil sample. However, the contamination is found to decrease with the increase in the temperature of the oil sample. The oil sample with maximum concentration of graphene nanoparticles has a DDF value eight times that of transformer oil. Hence, as the concentration of graphene nanoparticles is increased in the oil sample, the DDF value is increased. The is due to the agglomeration effects of nanoparticles that occur at higher concentrations. In addition, due to the presence of moisture content in the nanofluid, there is a chance of oxidation that may occur in the nanofluid, which will result in a higher DDF value. Moreover, improper storage of oil samples can also cause contamination due to dust and dirt particles. Thus, if the utmost care is taken during the preparation of a nanofluid and in storing the oil samples, DDF value can be reduced, and contamination of the transformer oil can be avoided.

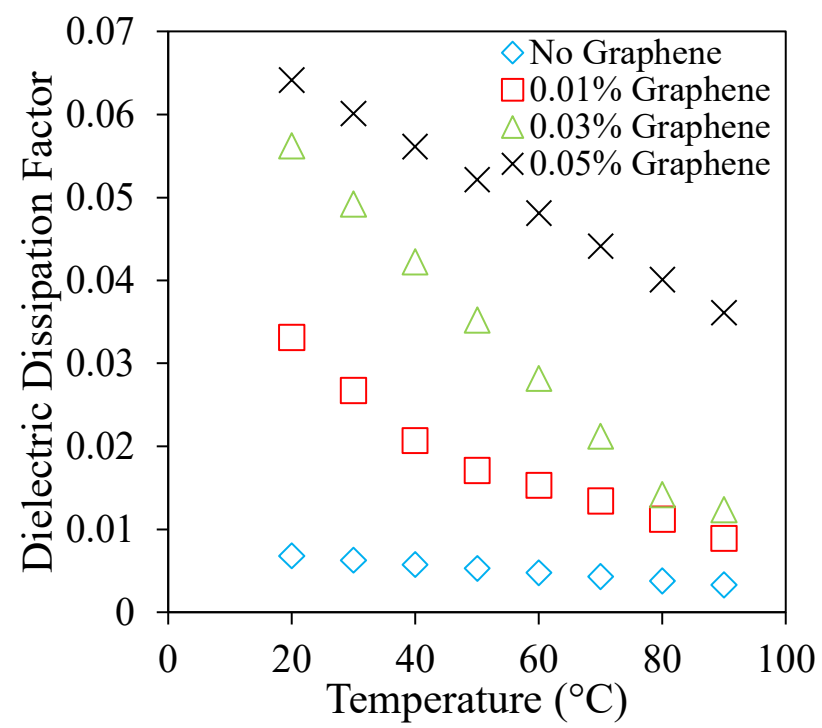

Figure 8. Variation of dielectric dissipation factor of graphene-transformer oil nanofluid with temperature. 


\section{Conclusions}

Enhancement in thermophysical and electrical properties of graphene-transformer oil nanofluid are experimentally studied for three different weight concentrations $(0.01,0.03$, and $0.05 \%)$. Experiments were carried out to find viscosity, density, surface tension, electrical resistivity, electrical conductivity, and dielectric dissipation factor for various temperatures ranging from $20^{\circ} \mathrm{C}$ to $90{ }^{\circ} \mathrm{C}$. The physical mechanisms responsible for the enhancement in thermophysical and electrical properties are discussed clearly. Based on the results, it is observed that the addition of nanoparticles increases the density and viscosity of the graphene-transformer oil nanofluid with an average enhancement of $2.5 \%$ and $16.6 \%$, respectively, from the base fluid. The increase in weight concentration of nanoparticles improves the Brownian motion of the nanoparticle due to which uniform distribution of temperature occurs in the nanofluid. Moreover, an increase in the addition of nanoparticles and temperature causes a reduction in surface tension of nanofluid, and a maximum reduction of $10.1 \%$ is observed for the highest weight concentration of graphene-transformer nanofluid. At higher temperatures, the vibration of nanoparticles increases, which in turn, decreases the cohesive force between these particles. In addition, adsorption of nanoparticles at liquid-vapor interface occurs due to the hydrophobic nature of graphene, which is attributed to the reduction in surface tension value for the maximum weight concentrations of nanofluid. Moreover, the specific resistance of graphene-transformer oil nanofluid decreases for all the weight concentrations and a maximum reduction of $79 \%$ is noted at $90{ }^{\circ} \mathrm{C}$ and for the maximum concentration of $0.05 \%$ when compared to transformer oil. In addition, it is concluded that all the properties that are measured for the nanofluid are within the limits of IS 335 standards, and thus, the results will be highly useful for the design of thermal energy storage systems and power transmission/distribution systems.

Author Contributions: Conceptualization, L.G.A.; Formal analysis, C.A. and S.P.; Project administration, L.G.A.; Supervision, L.G.A. and R.N.; Writing-original draft, S.M. and R.N.; Writing—review \& editing, J.R.B. and S.W. All authors have read and agreed to the published version of the manuscript.

Funding: This research received no external funding.

Acknowledgments: The authors thank Devesh Upadhyaya, TRU-FIL Limited, Navi Mumbai, Maharashtra for lending us help to conduct experiments of specific resistivity and dielectric dissipation factor. The authors are also grateful to R. Jaya Seelan of Karunya Institute of Technology and Sciences for helping us to conduct the experiments to measure the surface tension, viscosity, and density of nanofluids. The seventh author acknowledges the support provided by the "Research Chair Grant" National Science and Technology Development Agency (NSTDA) and the "KMUTT 55th Anniversary Commemorative Fund".

Conflicts of Interest: The authors declare no conflict of interest.

\section{References}

1. Miao, J.; Dong, M.; Ren, M.; Wu, X.; Shen, L.; Wang, H. Effect of nanoparticle polarization on relative permittivity of transformer oil-based nanofluids. J. Appl. Phys. 2013, 113, 204103. [CrossRef]

2. Rajňak, M.; Kurimský, J.; Cimbala, R.; Čonka, Z.; Bartko, P.; Šuga, M.; Paulovičová, K.; Tóthová, J.; Karpets, M.; Kopčanský, P.; et al. Statistical analysis of AC dielectric breakdown in transformer oil-based magnetic nanofluids. J. Mol. Liq. 2020, 309, 113243. [CrossRef]

3. Samy, A.M.; Ibrahim, M.E.; Abd-Elhady, A.M.; Izzularab, M.A. On electric field distortion for breakdown mechanism of nanofilled transformer oil. Int. J. Electr. Power Energy Syst. 2020, 117, 105632. [CrossRef]

4. Raof, N.A.; Yunus, R.; Rashid, U.; Azis, N.; Yaakub, Z. Effect of molecular structure on oxidative degradation of ester based transformer oil. Tribol. Int. 2019, 140, 105852. [CrossRef]

5. Salama, M.M.; Mansour, D.-E.A.; Daghrah, M.; Abdelkasoud, S.M.; Abbas, A.A. Thermal performance of transformers filled with environmentally friendly oils under various loading conditions. Int. J. Electr. Power Energy Syst. 2020, 118, 105743. [CrossRef]

6. Nimmagadda, R.; Reuven, R.; Asirvatham, L.G.; Wongwises, S. Thermal Management of Electronic Devices Using Gold and Carbon Nanofluids in a Lid-Driven Square Cavity under the Effect of Variety of Magnetic Fields. IEEE Trans. Compon. Packag. Manuf. Technol. 2020, 1-13. [CrossRef] 
7. Returi, M.C.; Konijeti, R.; Dasore, A. Heat transfer enhancement using hybrid nanofluids in spiral plate heat exchangers. Heat Transf.-Asian Res. 2019, 48, 3128-3143. [CrossRef]

8. Konda, J.R.; N.P., M.R.; Konijeti, R.; Dasore, A. Effect of non-uniform heat source/sink on MHD boundary layer flow and melting heat transfer of Williamson nanofluid in porous medium. Multidiscip. Model. Mater. Struct. 2019, 15, 452-472. [CrossRef]

9. Manova, S.; Asirvatham, L.G.; Nimmagadda, R.; Bose, J.R.; Wongwises, S. Cooling of high heat flux electronic devices using ultra-thin multiport minichannel thermosyphon. Appl. Therm. Eng. 2020, 169, 114669. [CrossRef]

10. Manova, S.; Asirvatham, L.G.; Nimmagadda, R.; Bose, J.R.; Wongwises, S. Feasibility of using multiport minichannel as thermosyphon for cooling of miniaturized electronic devices. Heat Transf. 2020, 1-23. [CrossRef]

11. Ramezanizadeh, M.; Hossein, M.; Alhuyi, M. A review on the utilized machine learning approaches for modeling the dynamic viscosity of nano fluids. Renew. Sustain. Energy Rev. 2019, 114, 1-15. [CrossRef]

12. Zhang, Y.; Xu, X. Curie temperature modeling of magnetocaloric lanthanum manganites using Gaussian process regression. J. Magn. Magn. Mater. 2020, 512, 166998. [CrossRef]

13. Estellé, P.; Cabaleiro, D.; Gawel, Ż.; Lugo, L.; Murshed, S.M.S. Current trends in surface tension and wetting behavior of nano fluids. Renew. Sustain. Energy Rev. 2018, 94, 931-944. [CrossRef]

14. Zhang, Y.; Xu, X. Physica C: Predicting doped MgB 2 superconductor critical temperature from lattice parameters using Gaussian process regression. Phys. C Supercond. Its Appl. 2020, 573, 1353633. [CrossRef]

15. Zhang, Y.; Xu, X. Predicting As x Se 1 - x Glass Transition Onset Temperature. Sci. Bulletin. 2020, 64, 1-6. [CrossRef]

16. Zhang, Y.; Xu, X. Predicting the thermal conductivity enhancement of nanofluids using computational intelligence. Phys. Lett. A 2020, 384, 30-32. [CrossRef]

17. Mahian, O.; Kolsi, L.; Amani, M.; Estellé, P.; Ahmadi, G.; Kleinstreuer, C.; Marshall, J.S.; Taylor, R.A.; Abu-Nada, E.; Rashidi, S.; et al. Recent advances in modeling and simulation of nanofluid flows—Part II: Applications. Phys. Rep. 2019, 791, 1-59. [CrossRef]

18. Zhang, Y.; Xu, X. Relative cooling power modeling of lanthanum manganites using Gaussian process regression. RSC Adv. 2020, 10, 20646-20653. [CrossRef]

19. Baghban, A.; Kahani, M.; Alhuyi, M.; Hossein, M. Sensitivity analysis and application of machine learning methods to predict the heat transfer performance of CNT / water nanofluid flows through coils. Int. J. Heat Mass Transf. 2019, 128, 825-835. [CrossRef]

20. Zeng, Y.-X.; Zhong, X.-W.; Liu, Z.-Q.; Chen, S.; Li, N. Preparation and Enhancement of Thermal Conductivity of Heat Transfer Oil-Based MoS2 Nanofluids. J. Nanomater. 2013, 2013, 1-6.

21. Li, D.; Xie, W.; Fang, W. Preparation and properties of copper-oil-based nanofluids. Nanoscale Res. Lett. 2011, 6, 373. [CrossRef] [PubMed]

22. Rafiq, M.; Lv, Y.; Zhou, Y.; Ma, K.; Wang, W.; Li, C.; Wang, Q. Use of vegetable oils as transformer oils-A review. Renew. Sustain. Energy Rev. 2015, 52, 308-324. [CrossRef]

23. Cao, Y.; Irwin, P.C.; Younsi, K. The future of nano dielectrics in the electrical power industry. IEEE Trans. Dielectr. Electr. Insul. 2004, 11, 797-807.

24. Nguyen, C.; Desgranges, F.; Galanis, N.; Roy, G.; Maré, T.; Boucher, S.; Mintsa, H.A. Viscosity data for Al2O3-water nanofluid-Hysteresis: Is heat transfer enhancement using nanofluids reliable? Int. J. Therm. Sci. 2008, 47, 103-111. [CrossRef]

25. Hanai, M.; Hosomi, S.; Kojima, H.; Hayakawa, N.; Okubo, H. Dependence of TiO2 and ZnO nanoparticle concentration on electrical insulation characteristics of insulating oil. In Proceedings of the IEEE Conference on Electrical Insulation and Dielectric Phenomena (CEIDP '13), Nagoya, Japan, 20-23 October 2013; pp. 780-783.

26. Karthik, R.; Raja, T.S.R.; Madavan, R. Enhancement of Critical Characteristics of Transformer Oil Using Nanomaterials. Arab. J. Sci. Eng. 2012, 38, 2725-2733. [CrossRef]

27. Beheshti, A.; Shanbedi, M.; Heris, S.Z. Heat transfer and rheological properties of transformer oil-oxidized MWCNT nanofluid. J. Therm. Anal. Calorim. 2014, 118, 1451-1460. [CrossRef]

28. Pugazhendhi, S.C. Experimental evaluation on dielectric and thermal characteristics of nano filler added transformer oil. In Proceedings of the 2012 International Conference on High Voltage Engineering and Application, Shanghai, China, 17-20 September 2012; pp. 207-210. 
29. Botha, S.S.; Ndungu, P.G.; Bladergroen, B.J. Physicochemical Properties of Oil-Based Nanofluids Containing Hybrid Structures of Silver Nanoparticles Supported on Silica. Ind. Eng. Chem. Res. 2011, 50, 3071-3077. [CrossRef]

30. Asadi, A.; Aberoumand, S.; Moradikazerouni, A.; Pourfattah, F.; Żyła, G.; Estellé, P.; Mahian, O.; Wongwises, S. Nguyen, H.M.; Arabkoohsar, A. Recent advances in preparation methods and thermophysical properties of oil-based nano fl uids: A state-of-the-art review. Powder Technol. 2019, 352, 209-226. [CrossRef]

31. Benos, L.; Sarris, I. Analytical study of the magnetohydrodynamic natural convection of a nanofluid filled horizontal shallow cavity with internal heat generation. Int. J. Heat Mass Transf. 2019, 130, 862-873. [CrossRef]

32. Benos, L.T.; Karvelas, E.G.; Sarris, I.E. Crucial effect of aggregations in CNT-water nano fluid magnetohydrodynamic natural convection. Therm. Sci. Eng. Prog. 2019, 11, 263-271. [CrossRef]

33. Bashirnezhad, K.; Safaei, S.; Reza, M.; Marjan, G.; Mahidzal, D. Viscosity of nanofluids: A review of recent experimental studies. Int. Commun. Heat Mass Transf. 2016, 73, 114-123. [CrossRef]

34. Nimmagadda, R. Buoyancy-driven heat transfer performance of pure and hybrid nanofluids in minienclosure. J. Thermophys. Heat Transf. 2018, 32, 570-579. [CrossRef]

35. Konakanchi, H.; Vajjha, R.; Misra, D.; Das, D. Electrical conductivity measurements of nanofluids and development of new correlations. J. Nanosci. Nanotechnol. 2011, 11, 6788-6795. [CrossRef]

36. Ahammed, N.; Asirvatham, L.G.; Wongwises, S. Effect of volume concentration and temperature on viscosity and surface tension of graphene-water nanofluid for heat transfer applications. J. Therm. Anal. Calorim. 2015, 123, 1399-1409. [CrossRef]

37. Godson, L.; Raja, B.; Lal, D.M.; Wongwises, S. Enhancement of heat transfer using nanofluids-An overview. Renew. Sustain. Energy Rev. 2010, 14, 629-641. [CrossRef]

(C) 2020 by the authors. Licensee MDPI, Basel, Switzerland. This article is an open access article distributed under the terms and conditions of the Creative Commons Attribution (CC BY) license (http://creativecommons.org/licenses/by/4.0/). 